\title{
Effect of low dose, short-term creatine supplementation on muscle power output in elite youth soccer players
}

Aquiles Yáñez-Silva', Cosme F. Buzzachera², Ivan Da C. Piçarro³ ${ }^{3}$ Renata S. B. Januario², Luis H. B. Ferreira ${ }^{4}$ Steven R. McAnulty ${ }^{5}$, Alan C. Utter ${ }^{5}$ and Tacito P. Souza-Junior ${ }^{4,5^{*}}$

\begin{abstract}
Background: To determine the effects of a low dose, short-term Creatine monohydrate ( $\mathrm{Cr}$ ) supplementation ( 0 . 03 g.kg. $\mathrm{d}^{-1}$ during $14 \mathrm{~d}$ ) on muscle power output in elite youth soccer players.

Methods: Using a two-group matched, double blind, placebo-controlled design, nineteen male soccer players (mean age $=17.0 \pm 0.5$ years) were randomly assigned to either $\mathrm{Cr}(N=9)$ or placebo $(N=10)$ group. Before and after supplementation, participants performed a 30s Wingate Anaerobic Test (WAnT) to assess peak power output (PPO), mean power output (MPO), fatigue index (Fl), and total work.

Results: There were significant increases in both PPO and MPO after the $\mathrm{Cr}$ supplementation period $(P \leq 0.05)$ but not the placebo period. There were also significant increases in total work, but not $\mathrm{Fl}$, after the $\mathrm{Cr}$ supplementation and placebo periods $(P \leq 0.05)$. Notably, there were differences in total work between the $\mathrm{Cr}$ and placebo groups after $(P \leq 0.05)$ but not before the $14 \mathrm{~d}$ supplementation period.
\end{abstract}

Conclusion: There is substantial evidence to indicate that a low-dose, short-term oral $\mathrm{Cr}$ supplementation beneficially affected muscle power output in elite youth soccer players.

Keywords: Creatine supplementation, Wingate test, Anaerobic performance

\section{Background}

The physiological demands of soccer require a welldeveloped aerobic and anaerobic fitness of the players [1]. Although the relevance of aerobic fitness levels in soccer has been confirmed by previous studies [2, 3], it is currently recognized that the most decisive actions during a soccer game are covered by anaerobic metabolism [4]. Indeed, anaerobic energy release plays a key role on the performance of a number of relevant activities during a soccer match, such as sprinting, jumping, tackling, kicking, and changes of direction [5], which may determine the final outcome of a game.

Previous research has shown that maximal or near maximal exercise bouts require a high skeletal muscle

\footnotetext{
* Correspondence: tacitojr2009@hotmail.com

${ }^{4}$ Department of Physical Education, Research Group on Metabolism, Nutrition and Strength Training, Curitiba, Brazil

${ }^{5}$ Department of Health and Exercise Science, Appalachian State University, Boone, USA

Full list of author information is available at the end of the article
}

adenosine triphosphate (ATP) turnover rate [6]. As intramuscular ATP storage is able to sustain muscular activity for only few seconds, ATP must continually be resynthesized for activity to continue. Gaitanos et al. [6] have reported that the majority of the energy required to resynthesize ATP during short-term, maximal exercise bouts is primarily provided by a combination of phosphocreatine $(\mathrm{PCr})$ degradation and anaerobic glycolysis. However, when PCr becomes depleted, performance deteriorates because ATP cannot be resynthesized at the rate required. That perspective has led some researchers to suggest that interventions, which increase resting levels of $\mathrm{PCr}$ availability, might delay $\mathrm{PCr}$ depletion and attenuate the decline in ATP provision during maximal or near maximal exercise bout [7]. Moreover, it has been suggested that higher level of $\mathrm{PCr}$ availability might accelerate the rate of $\mathrm{PCr}$ resynthesis after multiple bouts of intense exercise $[7,8]$. 
A popular dietary strategy for increasing resting levels of $\mathrm{PCr}$ availability and/or maximizing the team sports players' capacity to perform high intensity, exercise bouts is supplementation with oral Creatine monohydrate $(\mathrm{Cr})$. Indeed, a number of studies confirmed that short-term, Cr supplementation (20-30 $\mathrm{gd}^{-1}$ during 3-6 days), in amounts substantially in excess of the normal dietary intake, can elevate the total muscle $\mathrm{Cr}$ content $(\mathrm{PCr}+\mathrm{Cr})$ by approximately $20 \%$, one third of which is in the form of $\mathrm{PCr}[7,9,10]$. However, the results of studies investigating the effects of short-term, $\mathrm{Cr}$ supplementation on maximal exercise performance have been equivocal. Several studies have demonstrated an improved high intensity exercise performance after short-term, Cr supplementation [7, 8, 11, 12], whereas several others have reported no beneficial effect $[13,14]$. Some of these conflicting results are likely to be associated with differences in the $\mathrm{Cr}$ dosing regimens for the duration of the investigation. Whereas the majority of the studies used a typical $\mathrm{Cr}$ supplementation regimen including a "loading phase" of about 20 to 25 g.d ${ }^{-1}\left(0.3\right.$ g.kg.d $\left.{ }^{-1}\right)$ for 5 to 7 days to maximize muscle total $\mathrm{Cr}$ content, followed by a "maintenance phase" of about 2 to 5 g.d ${ }^{-1}$ [15], more recent studies have used alternative $\mathrm{Cr}$ supplementation regimens with doses of $\mathrm{Cr}$ as low as 2 to $5 \mathrm{g.d} \mathrm{d}^{-1}$ $\left(0.03\right.$ g.kg. $\left.\mathrm{d}^{-1}\right)$ for a longer period of 2 to 6 weeks without using a prior "loading phase" [16-18]. Importantly, both $\mathrm{Cr}$ dosing regimens can increase total muscle $\mathrm{Cr}$ content and promote ergogenic effects. A recent study presented by Rawson et al. [12] has shown that ingesting low doses of $\mathrm{Cr}$ as low as $\sim 2.3{\mathrm{~g} . \mathrm{d}^{-1}}^{-1}$ $\left(0.03\right.$ g.kg.d $\left.{ }^{-1}\right)$ for 6 weeks significantly increased the plasma $\mathrm{Cr}$ levels and enhanced the resistance to fatigue during multiple and high intensity exercise bouts. Although this study has found the lowest effective dose of $\mathrm{Cr}$ seen in the current literature, it is clear the duration of the $\mathrm{Cr}$ supplementation period was extended beyond the usual duration of typical $\mathrm{Cr}$ supplementation regimens $[12,18]$. To the authors' knowledge, the minimum duration of supplementation with $\mathrm{Cr}$ that is required to promote ergogenic effects on performance when ingesting doses of $\mathrm{Cr}$ as low as 2 to 5 g.d $\mathrm{d}^{-1}\left(0.03\right.$ g.kg. $\left.\mathrm{d}^{-1}\right)$ has not been clearly defined. However, there is a shortage of scientific data concerning the possible effects of oral $\mathrm{Cr}$ monohydrate supplementation on specific performance in sports such as soccer, which consists of intermittent repeated bouts of high-intensity exercise. The effect of $\mathrm{Cr}$ supplementation on young competitive athletes has received much less research attention. Therefore, the purpose of this study was to examine whether a low dose of 0.03 g.kg. $\mathrm{d}^{-1}$ of $\mathrm{Cr}$ supplementation for a short duration (only 14 days) affects muscle power output in a group of elite youth soccer players.

\section{Methods}

\section{Subjects}

Nineteen elite youth soccer players volunteered to participate in the study, which was performed in accordance with the Helsinki Declaration of 1975. The research was approved by the Ethics Committee of the Federal University of São Paulo. Each participant and parent gave their written informed consent after explanation of the study purpose, experimental procedures, possible risks and benefits. All the volunteers signed a free and informed consent term before participation. The selected players were members of the same team, played in national and international championships at the time of the investigation, and had a mean of $6.9 \pm 3.9$ years. of continuous soccer training and competition background. During the months before the beginning of the experimental period, players trained five times a week ( $~ 90$ to 120 min per session), with an official soccer match taking place at the end of the week. Each training session consisted mainly of technical and tactical skill development (60\% of the training time) and physical conditioning with emphasis on anaerobic and aerobic performance development. During the experimental period, players trained only two times a week and no official soccer match was played.

Experimental procedures were conducted in the middle stage of the competitive season (March to October), in the weeks where no official soccer matches were played. All players were free from current injuries limiting their ability to train and complete the experimental procedures of the study. However, to be eligible for participation, they had never been supplemented with $\mathrm{Cr}$ or maltodextrin or had never used anabolic steroids or beta-agonists. After baseline testing, players were ranked on muscle power output, and then matched pairs were randomly allocated in a double-blind fashion into a $\mathrm{Cr}$ $(N=9)$ or placebo $(N=10)$ group. Originally, there were twenty players (ten in each group), but in the second week after the beginning of the experimental period, one player left $\mathrm{Cr}$ group due external problems. Descriptive data of the participants are shown in Table 1.

\section{Study design}

This study used a two-group matched, double-blind, randomly assigned design. Before and after supplementation, participants completed two sessions, scheduled on different days with at least $48 \mathrm{~h}$ in-between session. During the first testing session, they underwent anthropometric measurements and a maximal graded exercise test using the protocol proposed by Helgerud et al. [2] to determine both their ventilatory threshold and maximal oxygen uptake. During the second testing session, they performed a 30s Wingate Anaerobic Test (WAnT) [17] to assess peak power output (PPO), mean power output (MPO), fatigue 
Table 1 Descriptive data of the participants $(N=19)$

\begin{tabular}{|c|c|c|}
\hline & Cr Supplementation $(N=9)$ & Placebo $(N=10)$ \\
\hline & Mean \pm SD & Mean \pm SD \\
\hline Age (yrs) & $16.9 \pm 0.6$ & $17.1 \pm 0.4$ \\
\hline Body weight (kg) & $66.8 \pm 3.2$ & $74.2 \pm 2.5^{\mathrm{a}}$ \\
\hline Height (cm) & $176.1 \pm 5.4$ & $178.4 \pm 4.0$ \\
\hline Body fat (\%) & $11.4 \pm 3.3$ & $11.7 \pm 3.1$ \\
\hline $\mathrm{O}_{2 \max }\left(\mathrm{mL} \cdot \mathrm{kg}^{-1} \cdot \mathrm{min}^{-1}\right)$ & $55.3 \pm 1.3$ & $51.1 \pm 2.1$ \\
\hline $\mathrm{VT}\left(\mathrm{mL} \cdot \mathrm{kg}^{-1} \cdot \mathrm{min}^{-1}\right)$ & $41.7 \pm 1.8$ & $40.7 \pm 0.9$ \\
\hline$H R_{\max }(b p m)$ & $195.8 \pm 1.8$ & $197.0 \pm 2.2$ \\
\hline
\end{tabular}

$O_{2 \max }$ maximal oxygen uptake, $V T$ ventilatory threshold, $H R_{\max }$ maximal heart rate

${ }^{\text {a}}$ Denotes a significant difference between the $\mathrm{Cr}$ and placebo groups $(P<0.05)$

index (FI), and total work. To avoid any circadian variation, all sessions were conducted at the same time of day $( \pm 1 \mathrm{~h})$. All players were familiarized with the testing procedures, having previously undertaken the tests many times. The test-retest intraclass correlation coefficients of the testing procedure variables used in this study were greater than 0.91 , and the coefficients of variation ranged from 0.9 to $7.3 \%$ (unpublished data). Before the beginning of the experimental period, players were instructed to refrain from heavy exercise and avoid alcoholic or caffeinated products in the $24 \mathrm{~h}$ preceding the tests and to present themselves at the experimental settings in a $2 \mathrm{~h}$ post-absorptive state.

\section{Supplementation procedure}

After baseline testing, soccer players were asked to consume either 0.03 g.kg. $\mathrm{d}^{-1}$ of creatine monohydrate (Phosphagen HP, EAS Inc., Golden, USA) or an equivalent volume of maltodextrin (Malto, NeoNutri Inc., Poços de Caldas, Brazil) for 14 days. Each supplement was measured using electronically calibrated scales and placed in identical coded airtight bags [11]. To avoid potential bias, supplements were prepared in powder form with similar texture and appearance. Players mixed the supplement powder into approximately $0.25 \mathrm{~L}$ of warmto-hot water for better dissolution of $\mathrm{Cr}$ [9] and ingested the solution with mid-day meals. They were instructed to ingest the supplements with food because this enhances body $\mathrm{Cr}$ retention [19]. $\mathrm{Cr}$ and placebo were administered in a double-blind fashion. Both $\mathrm{Cr}$ and placebo supplementation regimens were initiated right after the baseline testing and ended the same day of the first testing post supplementation session. Compliance, assessed by return of empty supplement airtight bags, with the supplement was greater than $99 \%$.

All players were asked to maintain their normal dietary behaviors throughout the study. Food diaries were given to each player to record food and fluid consumption for $4 \mathrm{~d}$ before the beginning of the experimental period, and players were asked to replicate this during posttraining testing. They were instructed how to report food and fluid consumption on food diaries by a coinvestigator trained in clinical nutrition.

\section{Testing procedures}

During the first session, players underwent anthropometric measurements. Body weight and height were measured according to the techniques described by Gordon et al. [20] and body fat was estimated from the measurements of seven skinfold thickness [21]. A maximal graded exercise test using the protocol suggested by Helgerud et al. [2] was then performed on a motorized treadmill (Millennium Super ATL, Imbramed, Porto Alegre, Brazil). After 10 min standard warm up consisting of running at $9 \mathrm{~km}$.h ${ }^{-1}$, the treadmill speed was increased by $1.0 \mathrm{~km} \cdot \mathrm{h}^{-1}$ every 5 min until the point of voluntary exhaustion. All players were verbally encouraged to undertake a maximum effort. The criteria for achieving a maximal oxygen uptake required participants to meet one of the following: (a) a plateau in oxygen uptake (change of $<150 \mathrm{~mL} \cdot \mathrm{min}^{-1}$ in the last three consecutive $15 \mathrm{~s}$ averages), (b) a respiratory exchange ratio of $>1.10$, and (c) a heart rate within 10 beats.$\min ^{-1}$ of the maximal level predicted by age [22]. Thus, maximal oxygen uptake was defined as the highest oxygen uptake value attained after reaching the aforementioned criteria. Ventilatory threshold (VT) was determined offline for each participant by plotting the ventilatory equivalent as a function of oxygen uptake in order to identify the point during test where this curve has its minimum value [23]. Both maximal oxygen uptake and ventilatory threshold measurements were used in this study as descriptive data (Table 1).

Oxygen uptake was measured on a breath-by-breath basis by a portable gas analysis system (K4b2, Cosmed, Rome, Italy). The system was calibrated using room air $(21 \% \mathrm{O} 2,0.03 \% \mathrm{CO} 2)$ and a certified gas mixture $(16 \%$ O2, 5\% CO2; Scott Medical Products, Plumsteadville, PA) before each test. In addition, the turbine flowmeter was calibrated with a $3 \mathrm{~L}$ syringe before each test.

During the second session, players performed a 30s Wingate Anaerobic Test (WAnT) [17]. Prior to testing, they were fitted for their optimal seat height on a cycle ergometer (Cybex Metabolic System, Lumex, Ronkonkoma, USA). The seat height was adjusted so that no more than $5^{\circ}$ of knee flexion was present when the leg was extended. After a warm-up period of 5 min pedaling at $60 \mathrm{rpm}$, interspersed with 4 all-out sprints lasting $5 \mathrm{~s}$, players were allowed $5 \mathrm{~s}$ of loadless pedaling to reach maximum cadence and were instructed to maintain maximal pedal speed throughout the 30 s once the resistance was applied $\left(0.09 \mathrm{~kg}^{-1}\right.$ body weight) [17, 24, 25]. Data were recorded for the 30 s using a computerized WAnT program. All players were verbally encouraged to 
undertake a maximum effort. MPO was defined as the average of six $5 \mathrm{~s}$ power outputs. PPO was defined as the highest $5 \mathrm{~s}$ power output during the $30 \mathrm{~s}$ test. FI was defined as $((\mathrm{PPO}-$ minimum power output $) / \mathrm{PPO}) \times 100$ and expressed as percent of power decrement (\%). Total work was defined as the summation of all six $5 \mathrm{~s}$ power outputs [13, 17, 24, 25].

\section{Statistical analysis}

Descriptive data are expressed as means \pm standard deviation. Data normality was evaluated with the ShapiroWilk $W$ test for normality [26]. A two-tailed unpaired $t$ test was used to compare baseline differences among the two groups' initial muscle power output measures [27]. A series of two-factor, group ( $\mathrm{Cr}$ supplementation and placebo) $\times$ time (pre- and post-supplementation), analysis of variance (ANOVA) with repeated measures was used to examine the pattern of change in muscle power output measures from before to after supplementation [28]. When a significant $F$ value was achieved, Scheffé post hoc procedures were used to locate the pairwise differences between the means. Statistical significance was assumed at $5 \%(P<0.05)$ a priori. All statistical analyses were performed using SPSS 18.0 for Windows (SPSS Inc., Chicago, USA). On the basis of a statistical power of 0.80, a moderately large effect size (0.25) [29], and a statistical significance of $0.05,10$ players were required for each of the cells.

\section{Results}

The descriptive data of the participants are presented in Table 1. There were no significant differences in participant characteristics between the $\mathrm{Cr}$ supplementation and placebo groups $(P>0.05)$, with exception of body weight. Specifically, the soccer players in the placebo group were significantly heavier than in the $\mathrm{Cr}$ supplementation group $(P<0.05)$.

The data for the PPO (expressed in Watts per kilogram of body weight; W. $\mathrm{kg}^{-1}$ ) produced pre- and postsupplementation are presented in Fig. 1a. There were significant increases in PPO after the $\mathrm{Cr}$ supplementation period $(8 \% ; P \leq 0.05)$ but not the placebo period $(3 \%)$. However, there were no differences in PPO between the $\mathrm{Cr}$ and placebo groups pre- and post-supplementation $(P>0.05)$, with no significant interaction between group and time $(P=0.35)$. Figure $1 \mathrm{~b}$ shows the data of MPO (expressed in Watts per kilogram of body weight; W. $\mathrm{kg}^{-1}$ ) produced pre- and post-supplementation in the $\mathrm{Cr}$ and placebo groups. Similarly to PPO, there were significant increases in $\mathrm{MPO}$ after the $\mathrm{Cr}$ supplementation period ( $8 \% ; P \leq 0.05)$ but not the placebo period (4\%). However, there were also no significant differences in MPO preand post-supplementation between the $\mathrm{Cr}$ and placebo

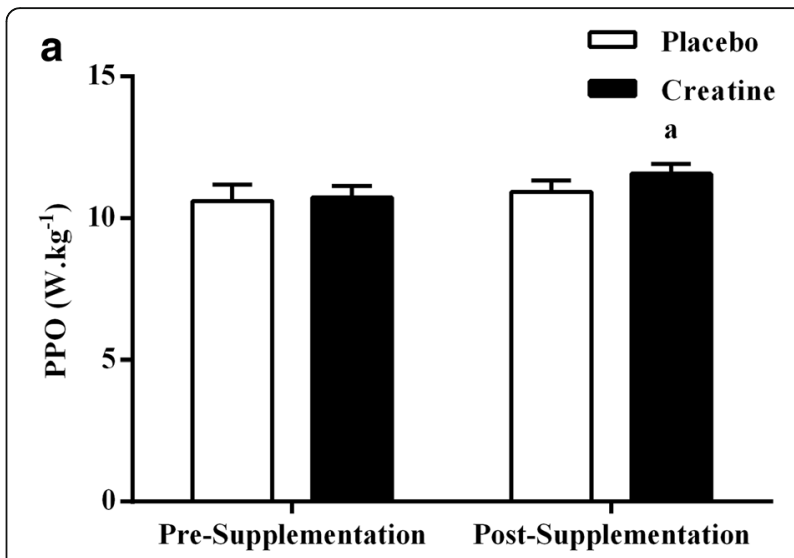

b

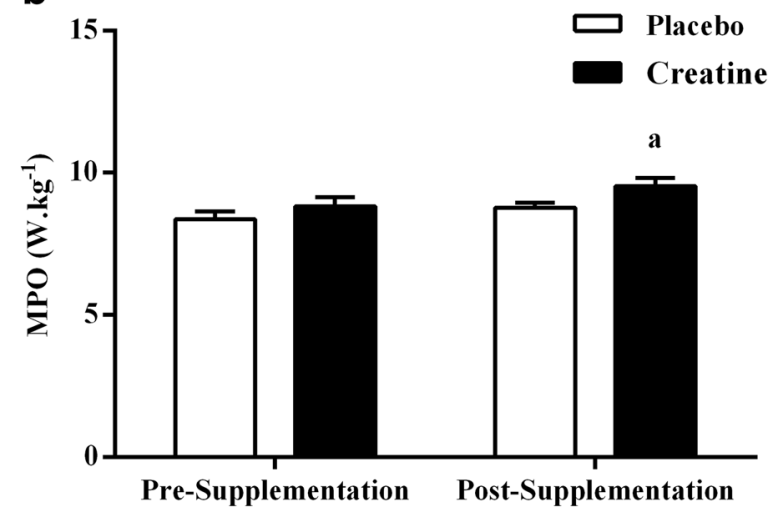

Fig. 1 Peak power output (PPO,W.kg ${ }^{-1}$; a) and mean power output $\left(\mathrm{MPO}, \mathrm{W}_{\mathrm{kg}} \mathrm{kg}^{-1}\right.$; b) before and after the $\mathrm{Cr}$ or placebo

supplementation period. ${ }^{a}$ Denotes a significant difference between pre- and post-supplementation $(P<0.05)$. Values are mean $\pm \mathrm{SE}$

groups $(P>0.05)$, with no significant interaction between group and time $(P=0.49)$.

The data for the total work (expressed in Joules per

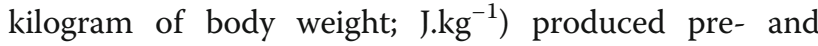
post-supplementation are presented in Fig. 2a. There were significant increases in total work after the $\mathrm{Cr}$ supplementation $(7 \%)$ and placebo $(6 \%)$ periods $(P<0.05)$. There were also significant differences in total work between the $\mathrm{Cr}$ and placebo groups after $(P<0.05)$ but not before the 14 days supplementation period $(P>0.05)$, with no significant interaction between group and time $(P=0.88)$. Figure $2 \mathrm{~b}$ shows the data of FI (expressed in percent of power decrement; \%) produced pre- and post-supplementation in the $\mathrm{Cr}$ and placebo groups. There were no significant changes in FI after the Cr supplementation or placebo period $(P=0.91)$. There were also no significant differences in FI pre- and postsupplementation between the $\mathrm{Cr}$ and placebo groups $(P>0.05)$, with no significant interaction between group and time $(P=0.58)$. 


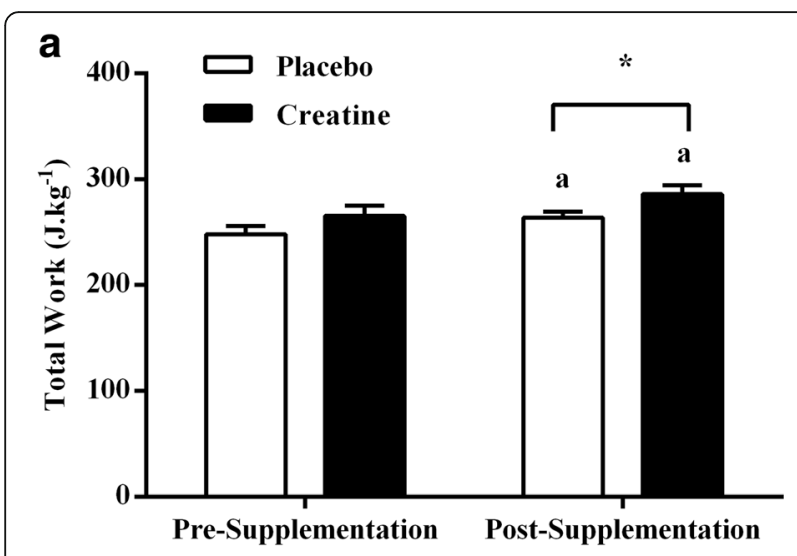

b

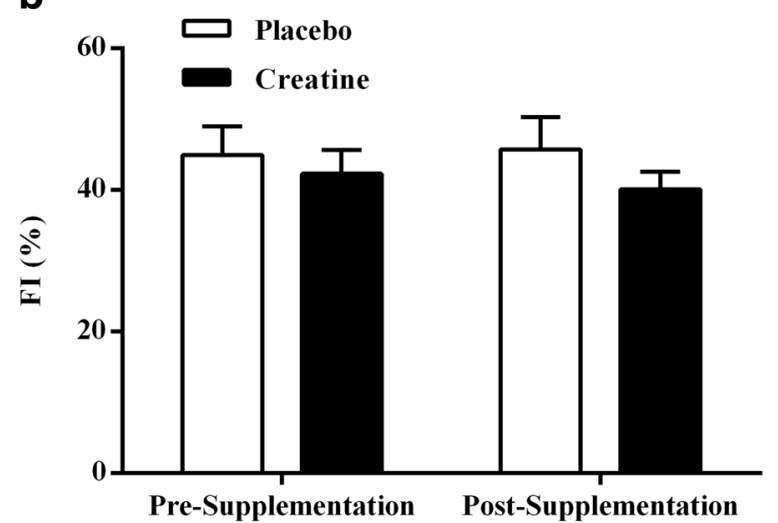

Fig. 2 Total work $\left({\mathrm{J} . \mathrm{kg}^{-1}}\right.$; a) and fatigue index (FI, \%; b) before and after the $\mathrm{Cr}$ or placebo supplementation period. ${ }^{\mathrm{a}}$ Denotes a significant difference between pre- and post-supplementation $(P<0.05)$. ${ }^{*}$ Denotes a significant difference between the $\mathrm{Cr}$ and placebo groups $(P<0.05)$. Values are mean $\pm \mathrm{SE}$

\section{Discussion}

The present study is the first to examine the effects of a low dose, short-term oral $\mathrm{Cr}$ monohydrate supplementation $\left(0.03\right.$ g.kg. $\mathrm{d}^{-1}$ during $\left.14 \mathrm{~d}\right)$ on muscle power output in elite youth soccer players. Few studies has been demonstrate that supplementation with $\mathrm{Cr}$ monohydrate in young soccer players improved soccer-specific skill performance compared with ingestion of placebo [30, 31]. Ostojic [31] in his study examined the effects of acute $\mathrm{Cr}$ monohydrate supplementation on soccer-specific performance in young soccer players. Twenty young male soccer players (16.6 \pm 1.9 years) participated in the study and were matched and allocated to 2 randomly assigned trials: ingesting $\mathrm{Cr}$ monohydrate supplement $(3 \times 10-\mathrm{g}$ doses $)$ or placebo for 7 days. Specific dribble test times improved significantly in the Cr group ( $13.0 \pm 1.5$ vs. $10.2 \pm 1.8 \mathrm{~s} ; p<.05)$ after supplementation protocol. Sprint-power test times were significantly improved after $\mathrm{Cr}$ monohydrate supplementation $(2.7 \pm 0.4$ vs. $2.2 \pm 0.5 \mathrm{~s} ; p<.05)$ as well as vertical jump height $(49.2 \pm 5.9$ vs. $55.1 \pm 6.3 \mathrm{~cm} ; p<.05)$ in $\mathrm{Cr}$ trial. $\mathrm{He}$ concluded that supplementation with $\mathrm{Cr}$ in young soccer players improved soccer-specific skill performance compared with ingestion of placebo [31]. The major finding was that despite there being no significant difference in post-supplementation muscle power output between $\mathrm{Cr}$ and placebo groups (with exception of total work), the $\mathrm{Cr}$ supplementation resulted in significant increases in PPO, MPO, and total work. These data suggest that $\mathrm{Cr}$ supplementation regimens with doses as low as 2 to 3 g. $\mathrm{d}^{-1}$ $\left(0.03\right.$ g.kg. $\left.\mathrm{d}^{-1}\right)$ for only 14 days beneficially affect muscle power output in youth soccer players. These data also indicate that a typical "loading phase" of $\mathrm{Cr}$ supplementation regimen including an increased dose of 20 to 25 g.d $\mathrm{d}^{-1}$ (0.3 g.kg. $\mathrm{d}^{-1}$ ) for 5 to 7 days to maximize muscle total $\mathrm{Cr}$ content [15] might not be necessary to enhance the team sports players' capacity to perform high intensity exercise bouts. Numerous researchers in the past [32-35] demonstrated that acute $\mathrm{Cr}$ supplementation has an ergogenic potential for highly trained soccer players. Cr-supplemented players showed an improved single and repeated sprint performance, increased jump ability, and enhanced endurance and agility, however, any of them aimed to analyze these effects in young soccer players nor with lower doses.

The efficacy of the low dose, short-term oral Cr supplementation protocol was demonstrated through the increases in PPO, MPO, and total work from the WAnT $(8,8$, and $7 \%$, respectively; Figs. 1 and 2$)$. These changes were of similar magnitude to previous studies [36-38] using a "loading phase" of about 20 to 25 g.d $\mathrm{d}^{-1}$ of $\mathrm{Cr}$. For example, Birch et al. [36] reported that ingesting $4 \times$ 5 g.d $\mathrm{d}^{-1}$ of $\mathrm{Cr}$ for $5 \mathrm{~d}$ resulted in significant increases in $\mathrm{PPO}, \mathrm{MPO}$, and total work performed in the first two of three maximal 30s isokinetic cycling tests. Using a similar Cr supplementation protocol of $4 \times 5$ g.d $\mathrm{d}^{-1}$ for $5 \mathrm{~d}$ and two maximal 30s isokinetic cycling tests, Casey et al. [37] found a $4 \%$ increase in the total work performed. These results, together with the present findings, confirm that the "loading phase" of the $\mathrm{Cr}$ supplementation is effective but unnecessary to enhance muscle power output in humans. These results also reinforce that a short-term $\mathrm{Cr}$ supplementation period $(<14$ days standard protocol) is sufficient to promote changes in muscle power output. These findings are consistent with the previous observations [39] that the majority of muscle $\mathrm{Cr}$ uptake appears to occur during the initial days of $\mathrm{Cr}$ supplementation, with a lower retention of the administered dose during subsequent supplementation days. Data from Hultman et al. [15] found that greater muscle creatine uptake during the first 14 days of low dose $\left(0.03\right.$ g.kg. $\left.\mathrm{d}^{-1}\right)$ supplementation in comparison with the last 14 days ( $30 \%$ or $14 \mathrm{~g}$ versus $12 \%$ or $5 \mathrm{~g})$.

The mechanisms behind the ergogenic effects of $\mathrm{Cr}$ ingestion are multifactorial and have yet to be fully elucidated [40]. It is speculated, however, that the increased capacity to generate power output after $\mathrm{Cr}$ ingestion 
might be attributed, at least in part, to increases in intramuscular total $\mathrm{Cr}$ concentration [7], increased ATP provision and attenuated reduction in ATP during maximal or near maximal exercise bout [8] and an increased potential for $\mathrm{Cr}$ acts as an cellular buffer on hydrogen ions produced during anaerobic glycolysis [41]. It is likely that this ability to generate more power output during high intensity, exercise bouts after oral $\mathrm{Cr}$ supplementation might allow athletes to train at higher intensities and facilitate their skeletal muscle adaptive responses to exercise training [42].

Most researchers have reported an increase in body weight after $\mathrm{Cr}$ ingestion [11, 18, 43, 44], although this topic has not been confirmed by some studies [12, 17]. These changes in body weight might be attributed, at least in part, to a positive nitrogen balance, which causes an increase in protein synthesis rate [41]. This possibility, however, appears to be more plausible as a result of longer periods of $\mathrm{Cr}$ intake combined with resistance training programs [8]. Thus, it is likely that gains in body weight are related more to greater water retention during short-term $\mathrm{Cr}$ supplementation than to leantissue accretion [15]. In the present study, however, there was no significant increase in body weight (unpublished data). Potentially, the increased total body water associated with $\mathrm{Cr}$ supplementation does not occur with low doses of $\mathrm{Cr}$ ingestion. Further research is required to examine different dosing protocols and assess total body water at multiple time points over several weeks. However, from a practical standpoint, this additional finding of absence of weight gain after a low-dose, shortterm $\mathrm{Cr}$ supplementation may be particularly advantageous for youth athletes who weight gain is undesirable, as this may affect in sports where the categories are divided by the weight.

Previous research has reported that $\mathrm{Cr}$ supplementation is related to negative side effects and health risks [44]. Anecdotal reports of gastrointestinal disturbances, dehydration, and muscle cramping have been associated with $\mathrm{Cr}$ supplementation [45]. Controlled studies on $\mathrm{Cr}$ supplementation, however, have failed to support this notion $[8,11]$. Consistent with this observation, no reports of gastrointestinal distress and/or medical problems/symptoms were reported by the young athletes during the $\mathrm{Cr}$ supplementation period. There was also no evidence of muscle cramping or muscle injury during soccer training and during testing trials (unpublished data). These results indicate that alternative $\mathrm{Cr}$ supplementation regimens with doses of $\mathrm{Cr}$ as low as 0.03 g.kg.d ${ }^{-1}$ for a shorter period of 2 weeks without using a prior "loading phase" are safe when used by youth athletes. This finding might be particularly useful for athletes who avoid a "loading phase" when beginning a $\mathrm{Cr}$ supplementation program. However, accepting that every sports and each position in that sports present different physical and physiological challenges, further researches should analyze the applicability of these short terms, low doses of $\mathrm{Cr}$ supplementation, focusing in the specificity of different sport and positions.

\section{Conclusions}

In summary, the present results indicate that a low-dose, short-term oral $\mathrm{Cr}$ monohydrate supplementation (0.03 g.kg. $\mathrm{d}^{-1}$ for $\left.14 \mathrm{~d}\right)$ beneficially affected muscle power output in youth soccer players, without any adverse side effects. Cr-supplemented soccer players showed improved PPO and MPO after the low-dose, short-term $\mathrm{Cr}$ supplementation $(P<0.05)$. However, placebo-supplemented soccer players also showed a small, but nonsignificant $(P>0.05)$, increase in both PPO and MPO. This small increase in PPO and MPO in placebo-supplemented soccer players, however, might explain, at least in part, the lack of significant differences between the groups following the short-term supplementation period. Therefore, we concluded that " $\mathrm{Cr}$ supplemented soccer players showed improved PPO, MPO, and total work after the low-dose, short-term $\mathrm{Cr}$ supplementation" mainly for two reasons: 1) $\mathrm{Cr}$ supplemented soccer players really showed increases in MPO, PPO, and total work after a low-dose, short-term $\mathrm{Cr}$ supplementation (within group differences, pre vs post analysis); and 2) placebo supplementation was not enough to cause any significant increase in both PPO and MPO in soccer players $(P>0.05)$.

The dose used in this study appears to be the lowest effective dose of $\mathrm{Cr}$ seen in the current literature [12], even when $\mathrm{Cr}$ supplementation periods are as short as 14 days. These findings of beneficial effects of a low dose, short-term $\mathrm{Cr}$ supplementation are of importance for applied sport scientists, nutritionists, and strength and conditioning professionals by helping them to design better nutritional interventions aimed to improve muscle power output in elite youth soccer players.

\section{Acknowledgements \\ We would like to thank all of the subjects who participated in the study as well as the Palmeiras F.C. and the research assistants in the Department of Health and Exercise Sciences at the Appalachian State University who helped with manuscript preparation. Dr. Tacito P. Souza-Junior is CNPq-Brazil Fellowship (\#216382/2014-9).}

\section{Funding}

Any funding source was used during the research and all expenses were shared between authors.

\section{Availability of data and materials}

Considering the Palmeiras FC is a professional football team, the team requested the non-presentation in the present section related to the results of individual data. In order to maintain the good relationship with the team and keep the window for further researches opened, we will not present the data and materials beyond that were present in the manuscript. 


\section{Authors' contributions}

AYS designed the study, oversaw data collection, data analysis and manuscript preparation. CFB assisted with study design, data analysis and manuscript preparation. ICP assisted with designed the study. RBJ assisted with manuscript preparation and statistical analyzes. LHBF assisted with manuscript design and helped to draft the manuscript. SRM and ACU assisted with data analysis and manuscript preparation. TSJ assisted with study design, data analysis and manuscript preparation. All authors read and approved the final manuscript.

\section{Competing interests}

The authors declare that they have no competing interests.

\section{Consent for publication}

Not applicable.

\section{Ethics approval and consent to participate}

The research was approved by the Ethics Committee of the Federa University of São Paulo. Each participant and parent gave their written informed consent after explanation of the study purpose, experimental procedures, possible risks and benefits. All the volunteers signed a free and informed consent term before participation.

\section{Author details}

'Dirección de Investigación, Universidad Mayor Santiago de Chile; Universidad Santo Tomás, Talca. Chile. Carrera de Educación Física, Santiago de Chile, Chile. ${ }^{2}$ Department of Physical Education, North University of Parana, Londrina, Brazil. ${ }^{3}$ School of Physical Education, Max Planck Faculty, Indaiatuba, Brazil. " Department of Physical Education, Research Group on Metabolism, Nutrition and Strength Training, Curitiba, Brazil. ${ }^{5}$ Department of Health and Exercise Science, Appalachian State University, Boone, USA.

\section{Received: 18 April 2016 Accepted: 1 February 2017}

\section{Published online: 07 February 2017}

\section{References}

1. Reilly T, Bangsbo J, Franks A. Anthopometric and physiological predisposition for elite soccer. J Sports Sci. 2000;18:669-83.

2. Helgerud J, Engen LC, Wisloff U, Hoff J. Aerobic endurance training improves soccer performance. Med Sci Sports Exerc. 2001;33:1925-31.

3. Castagna C, Manzi V, Impellizzeri F, Weston M, Barbero Alvarez JC. Relationship between endurance field tests and match performance in young soccer players. J Strength Cond Res. 2010;24:3227-33.

4. Stolen T, Chamari K, Castagna C, Wisloff U. Physiology of soccer. Sports Med. 2005;35:501-36.

5. Wragg CB, Maxwell NS, Doust JH. Evaluation of the reliability and validity of a soccer-specific field test of repeated sprint ability. Eur J Appl Physiol. 2000; 83:77-83.

6. Gaitanos GC, Williams C, Boobis LH, Brooks S. Human muscle metabolism during intermittent maximal exercise. J Appl Physiol. 1993;75:712-9.

7. Greenhaff PL, Bodin K, Soderlund K, Hultman E. Effect of oral creatine supplementation on skeletal muscle phosphocreatine resynthesis. Am J Physiol. 1994;66:E725-30.

8. Kreider RB, Ferreira M, Wilson M, Grindstaff P, Plisk S, Reinardy J, et al. Effects of creatine supplementation on body composition, strength, and sprint performance. Med Sci Sports Exerc. 1998;30:73-82.

9. Harris RC, Soderlund K, Hultman E. Elevation of creatine in resting and exercised muscle of normal subjects by creatine supplementation. Clin Sci. 1992;83:367-74.

10. Greenhaff PL, Casey A, Short AH, Harris R, Soderlund K, Hultman E. Effect of oral creatine supplementation on muscle torque during repeated bouts of maximal voluntary exercise in man. Clin Sci. 1993;84:565-71.

11. Izquierdo M, Ibanez J, Gonzales-Badillo JJ, Gorostiaga EM. Effects of creatine supplementation on muscle power, endurance, and sprint performance. Med Sci Sports Exerc. 2002;34:332-43

12. Rawson ES, Stec MJ, Frederickson SJ, Miles MP. Low-dose creatine supplementation enhances fatigue resistance in the absence of weight gain. Nutrition. 2011:27:451-5.

13. McKenna MJ, Morton J, Selig SE, Snow RJ. Creatine supplementation increases muscle total creatine but not maximal intermittent exercise performance. J Appl Physiol. 1999;87:2244-52.
14. Gilliam JD, Hohzonrn C, Martin D, Trimble MH. Effect of oral creatine supplementation on isokinetic torque production. Med Sci Sports Exerc. 2000;32:993-6

15. Hultman E, Soderlund K, Timmons JA, Cederblad G, Greenhaff PL. Muscle creatine loading in men. J Appl Physiol. 1996;81:232-7.

16. Thompson CH, Kemp GJ, Sanderson AL, Dixon RM, Styles P, Taylor DJ, et al. Effect of creatine on aerobic and anaerobic metabolism in skeletal muscle in swimmers. Br J Sports Med. 1996;30:222-5.

17. Hoffman JR, Stout JR, Falvo MJ, Kang J, Ratamess NA. Effect of low-dose, short-duration creatine supplementation on anaerobic exercise performance. J Strength Cond Res. 2005;19:260-4.

18. Eckerson JM, Bull AA, Moore GA. Effect of thirty days of creatine supplementation with phosphate salts on anaerobic working capacity and body weight in men. J Strength Cond Res. 2008;22:826-32.

19. Steenge GR, Simpson EJ, Greenhaff PL. Protein- and carbohydrate-induced augmentation of whole body creatine retention in humans. J Appl Physiol. 2000;89:1165-71.

20. Gordon CC, Chumlea WC, Roche AF. Stature, recumbent length, and weight In: Lohman TG, Roche AF, Martorell R, editors. Anthropometric standardization reference manual. Champaign: Human Kinetics; 1988.

21. Jackson AS, Pollock ML. Generalized equations for predicting body density of men. Br J Nutr. 1978;40:497-504.

22. Midgley AW, McNaughton LR, Polman R, Marchant D. Criteria for determination of maximal oxygen uptake: A brief critique and recommendations for future research. Sports Med. 2007;37:1019-28.

23. Baldari C, Guidetti L. A simple method for individual anaerobic threshold as predictor of maximal lactate steady state. Med Si Sports Exerc. 2000;32: 1798-802.

24. Snow RJ, McKenna MJ, Selig SE, Kemp J, Stathis CG, Zhao S. Effect of creatine supplementation on sprint exercise performance and muscle metabolism. J Appl Physiol. 1998;84:1667-73.

25. Zupan MF, Arata AW, Dawson LH, Payn TL, Hannon ME. Wingate anaerobic test peak power and anaerobic capacity classifications for men and women intercollegiate athletes. J Strength Cond Res. 2009;23:2598-604.

26. Shapiro SS, Wilk MB. An analysis of variance test for normality (complete samples). Biometrika. 1965:52:591-611.

27. Zar JH. Biostatistical analysis. Prentice Hall: Upper Saddle River; 1999.

28. Johnson RA, Wichern DW. Applied multivariate analysis. Prentice Hall: Upper Saddle River; 2002

29. Cohen J. Statistical power analysis for the behavioral sciences. Hillsdale: Erlbaum; 1988.

30. Mohebbi H, Rahnama N, Moghadassi M, Ranjbar K. Effect of creatine supplementation on sprint and skill performance in Young Soccer Players. Middle-East J Sci Res. 2012;12:397-401.

31. Ostojic SM. Creatine supplementation in young soccer players. Int I Sport Nutr Exerc Metab. 2004;14:95-103.

32. Bosco CC, Tranquilli J, Tihanyi R, Colli S, D'Ottavio S, Viru A. Influence of oral supplementation with creatine monohydrate on physical capacity evaluated in laboratory and field tests. Med Sport. 1995:48:391-7.

33. Cox G, Mujika I, Tumilty D, Burke L. Acute creatine supplementation and performance during a field test simulating match play in elite female soccer players. Int J Sport Nutr Exerc Metab. 2002;12:33-46.

34. Larson DE, Hunter GE, Trowbridge CA, Turk JC, Harbin PA, Torman SL. Creatine supplementation and performance during off-season training in female soccer players. Med Sci Sports Exerc. 1998:30:S264.

35. Mujika I, Padilla S, Ibanez J, Izquierdo M, Gorostiaga E. Creatine supplementation and sprint performance in soccer players. Med Sci Sports Exerc. 1998;32:518-25.

36. Birch $R$, Noble $D$, Greenhaff PL. The influence of dietary creatine supplementation on performance during repeated bouts of maximal isokinetic cycling in man. Eur J Appl Physiol. 1994;69:268-76.

37. Casey A, Constantin-Teodosiu D, Howell S, Hultman E, Greenhaff PL. Creatine ingestion favorably affects performance and muscle metabolsim during maximal exercise in humans. Am J Physiol. 1996:271:E31-7.

38. Zuniga JM, Housh TJ, Camic CL, Hendrix CR, Mielke M, Johnson GO, et al. The effects of creatine monohydrate loading on anaerobic performance and one-repetition maximum strength. J Strength Cond Res. 2012;26:1651-6.

39. Kambis KW, Pizzaedaz SK. Short-term creatine supplementation improves maximum quadriceps contraction in women. Int J Sport Nutr Exerc Metab. 2003;13:87-96. 
40. Cooper R, Naclerio F, Allgrove J, Jimenez A. Creatine supplementation with specific view to exercise/sports performance: an update. J Int Soc Sports Nutr. 2012;9:e33.

41. Balsom PD, Ekblom B, Soderlund K, Sjodin B, Hultman E. Creatine supplementation and dynamic high-intensity intermittent exercise. Scand J Med Sci Sports. 1993;3:143-9.

42. Volek JS, Duncan ND, Mazzetti SA, Staron RS, Putukian A, Gomez AL, et al. Performance and muscle fiber adaptations to creatine supplementation and heavy resistance training. Med Sci Sports Exerc. 1999;31:1147-56.

43. Rawson ES, Persky AM, Price TB, Clarkson PM. Effects of repeated creatine supplementation on muscle, plasma, and urine creatine levels. J Strength Cond Res. 2004;18:162-7.

44. Vandebuerie F, Vanden Eynde B, Vandenberghe K, Hespel P. Effect of creatine loading on endurance capacity and sprint power in cyclists. Int J Sports Med. 1998:19:490-5.

45. Poortmans JR, Francaux M. Adverse effects of creatine supplementation: fact or fiction. Sports Med. 2000:30:155-70.

Submit your next manuscript to BioMed Central and we will help you at every step:

- We accept pre-submission inquiries

- Our selector tool helps you to find the most relevant journal

- We provide round the clock customer support

- Convenient online submission

- Thorough peer review

- Inclusion in PubMed and all major indexing services

- Maximum visibility for your research

Submit your manuscript at www.biomedcentral.com/submit
Biomed Central 